\title{
Atrial fibrillation in acute Chagas disease acquired via oral transmission: a case report
}

\author{
Paulo Fernando Pimenta de Souza ${ }^{[1]}$, Rosane Cheble Domingues Pine ${ }^{[2]}$, \\ Francisco Lúzio de Paula Ramos ${ }^{[3]}$ and Ana Yecê das Neves Pinto ${ }^{[3]}$
}

\author{
[1]. Universidade do Estado do Pará, Belém, PA, Brasil. \\ [2]. Fundação Hospital de Clínicas Gaspar Viana, Belém, PA, Brasil. \\ [3]. Serviço de Atendimento Médico Unificado/Epidemiologia, Instituto Evandro Chagas, \\ Ministério da Saúde do Brasil, Ananindeua, PA, Brasil
}

\begin{abstract}
Atrial fibrillation (AF), a type of supraventricular arrhythmia increases the risk of thromboembolism. Chagas disease has been reported in the Brazilian Amazon region over approximately 20 years. Cardiac abnormalities are recorded in at least $50 \%$ of patients and among these, $3.3 \%$ develop AF. We describe a case of a 41-year-old man from Muaná, Pará State, who reported a 30-day history of a febrile illness. Acute Chagas disease was confirmed, and an electrocardiogram revealed AF. He was treated with antiparasitic and anti-arrhythmic drugs, beta blockers, and anticoagulants. Reversion to sinus rhythm was observed at his 9-month follow-up.
\end{abstract}

Keywords: Atrial fibrillation. Acute Chagas disease. Thromboembolism.

\section{INTRODUCTION}

Atrial fibrillation $(\mathrm{AF})$ is a tachyarrhythmia (supraventricular tachycardia) in which atrial stimulation occurs at very high frequencies (often $>400$ stimuli $/ \mathrm{min}$ ). AF, one of the most common sustained arrhythmias with clinical implications requires prompt intervention.

The current prevalence of AF is $1-2 \%$ of the general adult population. The incidence increases with age and the presence of heart disease, particularly when associated with arterial hypertension ${ }^{1}$. Clinically, patients may be asymptomatic or may present with symptoms including palpitations, dizziness, dyspnea, heart failure, and/or syncope. AF is associated with an increased and serious risk of thromboembolism, which however is usually underestimated ${ }^{2}$. The risk of ischemic stroke associated with $\mathrm{AF}$ increases with age and could be approximately $24 \%$ in patients aged $>80$ years ${ }^{3}$.

AF may occur in individuals without heart disease; however, it is more common in patients with heart disease including hypertension, cardiac valvular and coronary artery disease, and degenerative conditions. Acute AF is typically reversible and can be cured with the resolution of causative factors including

Corresponding author: Dra. Ana Yecê das Neves Pinto e-mail: ayneves87@hotmail.com

Received 6 November 2017

Accepted 23 March 2018 pericarditis and myocarditis, which are particularly known to occur in acute Chagas disease ${ }^{4,5}$.

In the Brazilian Amazon region, outbreaks or isolated cases of acute Chagas disease (ACD) in urban and non-urban populations have occurred endemically since 1988. In a series of cases studied over 15 years, the authors reported that acute heart impairment was observed in $50 \%$ of the cases including $\mathrm{AF}$ in $3.3 \%$, which was the direct cause of death in at least 1 case $^{6}$.

Patients with chronic Chagasic cardiomyopathy develop complications such as pulmonary and systemic emboli that often lead to death, for example, stroke endocardial murals. These conditions are related to the dilatation of cavities and ventricular dysfunction, causing slowing and stagnation of blood flow with associated inflammation of the endocardium. This finding was demonstrated experimentally based on functional changes observed in the microcirculation, increased vascular tone, stimulation of platelet aggregation, and the development of inflammatory substances with thrombotic properties such as thromboxane $\mathrm{A} 2$ and interleukin- ${ }^{7}$.

This present report contributes to a better understanding of the diagnosis and clinical management of this rare heart rhythm disorder based on the high incidence of ACD, which serves as a primary etiological contributor to $\mathrm{AF}$ in the Amazon region. Additionally, authors have provided evidence-based strategies regarding the optimal management of $\mathrm{AF}$ given the limited practical recommendations currently available. 


\section{CASE REPORT}

A 41-year-old man from Muaná in Pará State presented with a history of febrile illness on December 13, 2012. He complained of headache, myalgia, fatigue, as well as facial and lower limb edema. He denied cardiac symptoms at the onset of the disease. Physical examination revealed paleness of his skin, fever $\left(38.5^{\circ} \mathrm{C}\right)$, swelling of the face and malleolar edema in both legs. Pulmonary auscultation was normal. Cardiac auscultation revealed rhythm abnormalities, a heart rate of 100 beats per minute (bpm), and an arterial blood pressure of $120 / 80 \mathrm{mmHg}$. The patient denied alcoholism and history of heart or lung disease.

He reported that 5 neighbors were known to be sick during the same period and all were diagnosed with Chagas disease. This information guided the clinical epidemiological diagnosis for ACD acquired via oral transmission, i.e., disease transmitted during an outbreak limited in time. The diagnosis was confirmed based on epidemiological, clinical, and serological criteria despite negative results of parasitological examination (Table 1). Complementary electrocardiographic examination revealed AF with a mean heart rate of $100 \mathrm{bpm}$ (Figure 1A).

He was immediately administered benznidazole at a dose of $300 \mathrm{mg} /$ day, warfarin at a dose of $1 \mathrm{mg} /$ day, and atenolol at a dose of $25 \mathrm{mg} /$ day. The patient was followed with serial reviews including coagulation studies that measured the International Normalized Ratio and the prothrombin activity time (INR/PAT), electrocardiograms (EKG), and echocardiograms. After 6 days of treatment, his EKG remained abnormal and showed AF, but his heart rate had reduced to $77 \mathrm{bpm}$. Warfarin and beta-blocker doses were adjusted based on the INR/PAT and heart rate. During the same period, his echocardiogram revealed a slight increase in the left atrium normal ejection fraction despite the presence of septal hypokinesia and the absence of thrombus formation. His current echocardiogram was compared with an echocardiogram performed in May 2007, which showed normal results (Table 2).

At the end of the 60-day treatment regimen comprising benznidazole, the patient reported no complaints, and no clinical signs or symptoms were observed. However, an EKG demonstrated persistent AF.

During the $4^{\text {th }}$ month of treatment, the INR remained at 3.8 when the atenolol was discontinued, and chemical cardioversion was initiated using amiodarone at a dose of $600 \mathrm{mg} /$ day. After 10 days of use, the patient remained asymptomatic but demonstrated a flutter and a normal heart rate of $60 \mathrm{bpm}$ (Figure 1A and Figure 1B). After 20 days of amiodarone use, an echocardiogram demonstrated the same initial pattern, and the EKG continued to demonstrate atrial flutter.

Eventually, we decided to discontinue the administration of amiodarone and performed cardiac surgical ablation via a catheter. Surprisingly, 9 months after the institution of treatment (October 2013), reversion to sinus rhythm was observed during preprocedural assessment for surgical ablation. An EKG performed at the time was completely normal (Figure 1C).

\section{DISCUSSION}

This patient was diagnosed with ACD in January 2013 and followed-up over 9 months. Although his acute febrile illness occurred in October or November 2012, his diagnosis

TABLE 1: Results of parasitological and serological testing performed at follow-up post treatment with antiparasitic drugs.

Results

Examination performed 


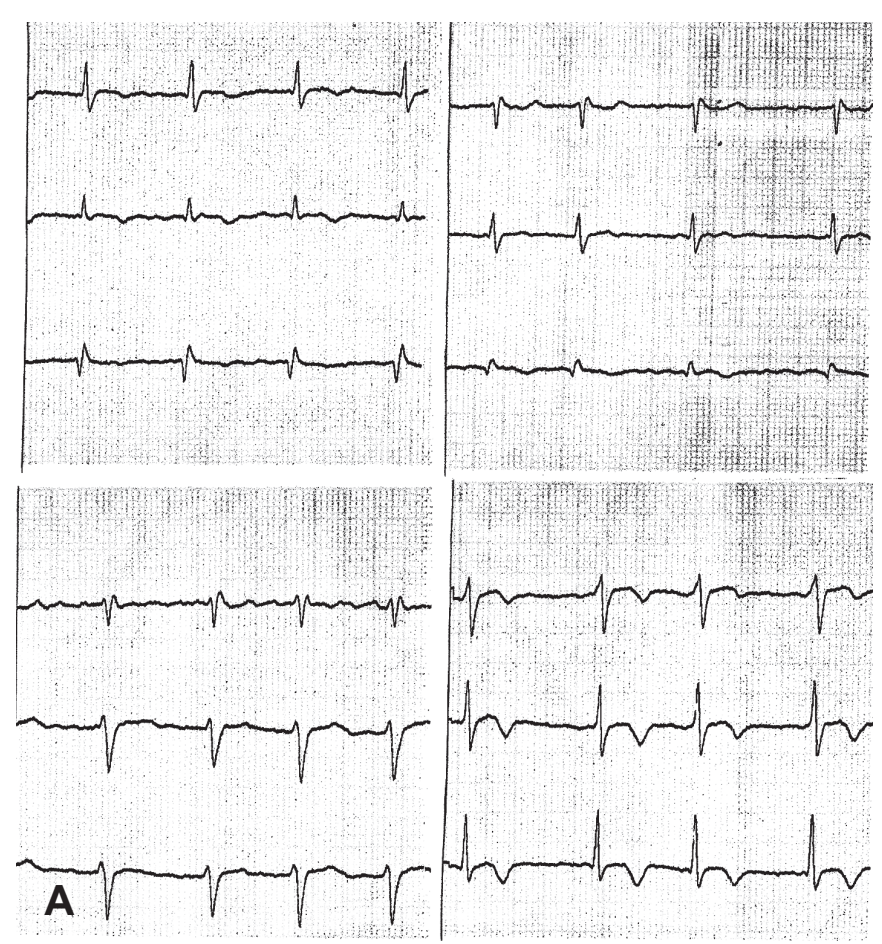

FIGURE 1: Electrocardiographic measurements. 1A. Electrocardiographic tracing obtained upon admission: atrial fibrillation and altered ventricular repolarization can be observed. 1B. Electrocardiographic tracing obtained at the $4^{\text {th }}$ month of follow-up post treatment: atrial flutter and altered ventricular repolarization can be observed. 1C. Electrocardiographic tracing obtained at the $9^{\text {th }}$ month of follow-up: sinus rhythm and normal ventricular repolarization can be observed.
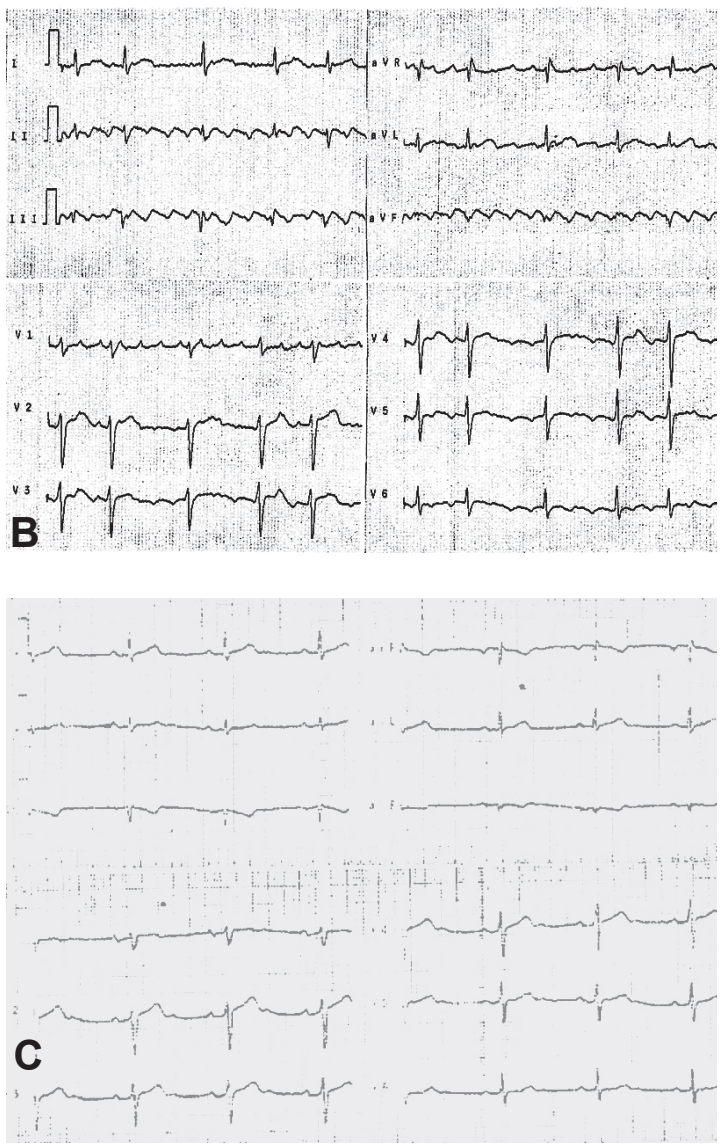

TABLE 2: Results of echocardiographic evaluation performed during follow-up.

\begin{tabular}{|c|c|c|c|c|c|c|}
\hline rear 2013 & $\begin{array}{l}\text { left atrium }(20- \\
40 \mathrm{~mm})\end{array}$ & $\begin{array}{l}\text { diastolic diameter } \\
\text { LV }(3-56 \mathrm{~mm})\end{array}$ & $\begin{array}{c}\text { systolic diameter LV } \\
(20-35 \mathrm{~mm})\end{array}$ & $\begin{array}{l}\text { septal wall } \\
(8-11 \mathrm{~mm})\end{array}$ & $\begin{array}{c}\text { posterior wall LV } \\
(8-11 \mathrm{~mm})\end{array}$ & $\begin{array}{c}\text { ejection fraction } \\
>57 \%\end{array}$ \\
\hline \multicolumn{7}{|l|}{ Month } \\
\hline January & 44 & 54 & 34 & 14 & 14 & 66.0 \\
\hline May & 51 & 59 & 38 & 11 & 11 & 64.0 \\
\hline December & 46 & 58 & 37 & 12 & 11 & 65.0 \\
\hline
\end{tabular}

LV: left ventricle.

was delayed. His clinical manifestations included a febrile syndrome over 20 days without signs or symptoms of cardiac disease. His physical examination revealed a high heart rate, which was detected and confirmed by an EKG, and AF secondary to acute heart impairment was also detected. After performing serial evaluations over 3 months, surgical ablation was attempted. Notably, during preprocedural monitoring for the surgical procedure, spontaneous reversion to sinus rhythm was detected.
AF can occur secondary to transient conditions such as myocarditis for which effectively treating the underlying cause may be the only action necessary to restore a normal heart rhythm ${ }^{8}$. In this patient, amiodarone administration was discontinued 3 months before the attempted surgical reversal.

Radiofrequency catheter ablation is used to treat drugrefractory AF. However, the procedure is associated with complications and significant mortality. Complications 
include pericardial effusion and tamponade, thromboembolic phenomena, pulmonary vein stenosis, phrenic nerve injury, and atrio-esophageal fistulae. The condition is defined as class I when it is symptomatic in young patients with structurally normal hearts without any response to or the development of adverse effects to at least 2 anti-arrhythmic drugs ${ }^{9}$. The condition is defined as class III in patients with reversible causes of AF, which includes the case of the patient reported in this paper.

AF or flutter has been reported in $4-12 \%$ of patients with Chagas disease in the chronic phase and is associated with cardiomegaly with serious consequences. In the advanced stages, these conditions are important sources of thrombi that can cause systemic and pulmonary thromboembolic phenomena resulting in stroke ${ }^{10,11}$.

Numerous cases of ACD were reported in the Amazon region approximately 20 years ago, and ACD-induced acute cardiac complications served as the leading cause of hospitalization. The longitudinal cohort studied by our group includes records of a case of fatal AF that probably occurred secondary to infection with Trypanosoma cruzi owing to delayed management. An 85-year-old man, with ACD was reported to have died secondary to a stroke. An EKG could not be performed in this patient owing to lack of time; however, retrospective evaluation of the clinical register suggested the role of potential AF-induced thromboembolism as a probable cause of death ${ }^{12}$. A study performed in the same region evaluated patients who had been hospitalized with manifestations of serious illness, and it was observed that $95 \%$ of patients had been hospitalized secondary to heart failure. Additionally, $10 \%$ demonstrated AF with spontaneous reversion to a normal sinus rhythm ${ }^{6}$.

In conclusion, the increased volume of the LA detected by a Doppler echocardiogram in this patient can be considered a useful marker of the potential risk of development of arrhythmia.

AF remains a challenge in clinical practice and therapeutic decisions for its management remain complex, particularly in patients presenting with conditions such as myocarditis caused by $T$. cruzi. Effective treatment of the underlying cause, i.e., chagasic infection was the most important intervention in our patient to restore normal heart rhythm, and this is therefore considered a transient and reversible situation.

Successful treatment in this case is attributable to early diagnosis of arrhythmia and its cause. Early diagnosis enabled prompt initiation of treatment to eliminate the direct cause and institution of thromboembolism prophylaxis using anticoagulation and also prevented ventricular dilatation. Our experience in this case suggests that non-invasive clinical management concomitant with strict clinical monitoring was the best option in this case and electrical cardioversion and ablation could be avoided.

\section{Financial support}

This study received funding/financial support from Instituto Evandro Chagas, Secretaria de Vigilância em Saúde (SVS), Ministério da Saúde do Brasil.

\section{Conflict of interest}

The authors declare that there is no conflict of interest.

\section{REFERENCES}

1. Stewart S, Hart CL, Hole DJ, McMurray JJV. Population prevalence, incidence and predictors of atrial fibrillation in the Reinfrew/Paisley study. Heart. 2001;86(5):516-21.

2. Almeida LG. Eletrocardiograma nos pacientes idosos. In: Goldwasser GP, editor. Eletrocardiograma Orientado para o Clínico. $3^{\text {rd }}$ edition. Rio de Janeiro: Editora Rubio; 2009. p. 381-96.

3. Mateos JCP, Mateos EIP, Lobo JT. Fibrilação atrial. In: Lopes AC, editor. Arritmias cardíacas. São Paulo: Editora Atheneu, 2004. p. 75-108.

4. Dias E, Laranja FS, Miranda A, Nobrega G. Chagas'disease. A clinical, epidemiologic and pathologic study. Circulation. 1956;14(6):1035-60.

5. Cançado JR, Brener Z. Terapêutica. In: Brener, Z, Andrade Z, editors. Trypanosoma cruzi e Doença de Chagas. Rio de Janeiro: Editora Guanabara Koogan. 1979. p.362-424.

6. Neves Pinto AY, Ferreira SMAG, Valente SAS, da Costa Valente V, Ferreira Jr AG. Alterações eletrocardiográficas durante e após tratamento com benzonidazol em fase aguda de doença de Chagas autóctone da Amazônia brasileira. Rev Pan-Amaz Saude. 2010;1(2):67-76.

7. Tanowitz HB, Burns ER, Sinha AK, Kahn NN, Morris SA, Factor $\mathrm{SM}$, et al. Enhanced platelets adherence and aggregation in Chagas disease: a potential pathogenic mechanism for cardiomyopathy. Am J Trop Med Hyg. 1990;43(3):247-81.

8. Goldwasser GP. Flutter e Fibrilação atrial. In: Goldwasser GP, editor. Eletrocardiograma Orientado para o Clínico. $3^{\text {rd }}$ edition. Rio de Janeiro: Editora Rubio; 2009. p. 246-9.

9. Zimerman LI, Fenelon G, Martinelli Filho M, Grupi C, Atié J, Lorga Filho A, et al. Diretrizes Brasileiras de Fibrilação Atrial. Arq Bras Cardiol. 2009;92(6 supl 1):1-39.

10. Maia IG, Sa RS, Loyola LH, Araujo PP, Monteiro SM, Amino JGC, et al. O nódulo sinusal na cardiopatia chagásica crônica. Arq Bras Cardiol. 1983;40(2):91-6.

11. Samuel J, Oliveira M, Correa de Araujo RR, Navarro MA, Muccillo G. Cardiac thrombosis and thromboembolism in chronic Chagas' heart disease. Am J Cardiol. 1983;52(1):147-51.

12. Pinto AYN, Farias JR, Marçal AS, Galucio AL, Costi RR, Valente VC, et al. Doença de Chagas aguda grave autóctone na Amazônia brasileira. Rev Para Med. 2007;21(2):7-12. 